\title{
Circulation of human coronaviruses OC43 and 229E in Córdoba, Argentina
}

\author{
María Emilia Ottogalli ${ }^{1}$ Pamela Elizabeth Rodríguez ${ }^{1}$. María Celia Frutos ${ }^{1} \cdot$ Laura Beatriz Moreno $^{2}$. \\ Lucía María Ghietto ${ }^{1}$. Cecilia Gabriela Cuffini ${ }^{1}$. Jorge Augusto Cámara ${ }^{1} \cdot$ María Pilar Adamo $^{1}$. \\ Laura Elena Valinotto ${ }^{3}$. Alicia Cámara ${ }^{1}$ (D)
}

Received: 25 June 2020 / Accepted: 25 October 2020 / Published online: 25 January 2021

(c) The Author(s), under exclusive licence to Springer-Verlag GmbH, AT part of Springer Nature 2021

\begin{abstract}
This is the first study of respiratory infections in Córdoba, Argentina, caused by endemic human coronavirus (HCoV)-OC43 and HCOV-229E, which circulated during 2011-2012 at a 3\% rate, either as single or multiple infections. They were detected mainly in children, but HCoV-229E was also found in adults. $\mathrm{HCoV}-229 \mathrm{E}$ was detected in five out of 631 samples $(0.8 \%)$, and $\mathrm{HCoV}-\mathrm{OC} 43$ was found in 14 out of $631(2.2 \%)$ samples. Clinical manifestations ranged from fever to respiratory distress, and a significant association of HCoV-229E with asthma was observed. Further studies and surveillance are needed to provide better clinical insights, early diagnosis, and medical care of patients, as well as to contribute to epidemiology modeling and prevention.
\end{abstract}

Viral acute respiratory infections (ARIs) are common and are one of the main causes of morbimortality worldwide. Young children, the elderly, patients with chronic diseases, and the immunosuppressed are at greatest risk, and in general, ARIs have direct and indirect costs for families, health services, and the global community [1-9]. Not only do viruses responsible for ARI have a major impact on human health, but they also continue to emerge, and as a consequence, their diagnosis and surveillance constitutes a milestone for the public health system.

Diagnostic methods based on molecular biology have allowed the identification of a number of human viruses, including human metapneumoviruses (HMPVs), human rhinoviruses (HRVs), human enteroviruses (HEVs), human coronaviruses (HCoVs) and human bocaviruses (HBoVs)

Handling Editor: John Ziebuhr.

Alicia Cámara

camaraalicia@yahoo.com.ar

1 Instituto de Virología “Dr. J. M. Vanella”, Facultad de Ciencias Médicas, Universidad Nacional de Córdoba, Córdoba, Argentina

2 Cátedra de Clínica Pediátrica, Facultad de Ciencias Médicas, Universidad Nacional de Córdoba, Córdoba, Argentina

3 Hospital de Niños “Dr. Ricardo Gutiérrez”, Buenos Aires, Argentina
$[10,11]$. In recent decades, epidemics related to emergent coronaviruses have occurred: Severe acute respiratory syndrome due to SARS-CoV in 2002-2003, Middle East respiratory syndrome caused by MERS-CoV (2012, cases continue till present), and the new coronavirus causing COVID-19, SARS-CoV-2, which reached pandemic level on March 11, 2020 [12-16]. Recombination events are responsible for the emergence of these new strains $[12,14]$, which are zoonotic, gain the ability to be transmitted from person to person, and are associated with a high mortality rate. As a result, studies on coronaviruses have intensified recently, although these viruses have been known since the 1930s, and human coronaviruses responsible for a major proportion of respiratory tract infections globally were identified already in 1965 [17].

Coronaviruses are ssRNA+ viruses. Transmission occurs via the respiratory and fecal-oral routes $[18,19]$. HCoVs are distributed worldwide, but the frequency and associated pathogenicity are unclear and are highly dependent on the case series studied, since the rate of detection can vary depending on the type of respiratory sample collected, the sensitivity of the diagnostic assay, and the years and seasons when patients were recruited [20]. The most common serotypes are $\mathrm{HCoV}-\mathrm{OC} 43$ and $\mathrm{HcoV}-229 \mathrm{E}$. It has been reported that they both show a marked seasonality, with infections more common during the winter (December through April in the Northern Hemisphere); however, HCoV-229E is sometimes only sporadically detected, and its circulation is 
significantly different each year [19,21]. Both cause mildto-severe respiratory infections, including pneumonia and bronchiolitis $[22,23]$, and they are the second-most frequently detected agent causing the common cold, after HRV $[5,7]$. HCOVs have also been associated with asthma and bronchitic hyperactivity, even in non-atopic patients [24]. $\mathrm{HCoV-OC} 43$ is more frequently detected and is often found to be the only pathogen in patients with lower ARI, while HCoV-229E has been associated with infections of immunocompromised individuals [19]. HCoV infections have been studied in infants of Buenos Aires, where they were detected in $2 \%$ of patients, always in coinfection with another viral agent [10]. On the other hand, a study in Australia shows that these two coronaviruses (mainly $\mathrm{HCoV}-\mathrm{OC} 43$ ) were the most common causes of influenza-like illness in children [25]. Yet, data on $\mathrm{HCoV}$ infection, its diagnosis, its clinical significance, and particularly, its circulation and seasonality in the Southern Hemisphere are scarce, with most of the data pertaining to countries in the Northern Hemisphere. Data from Argentina, which is located in the temperate zone of the Southern Hemisphere, are therefore of interest.

Coronaviruses have not been studied in Córdoba, and its detection has not been included in the routine diagnostic panel for ARI, even though it would contribute to differential diagnosis, handling and treatment of patients, and surveillance. Therefore, the goal of this study was to investigate the presence of endemic $\mathrm{HCoV}$, using molecular techniques, in hospitalized children and adult patients with symptoms of ARI in Córdoba, Argentina. Córdoba is a Mediterranean province located in the center of Argentina (latitude: $31^{\circ}$ $24^{\prime} 48^{\prime \prime}$ S, elevation: $395 \mathrm{~m}$ ). We investigated the circulation and frequency of HCoV-OC43 and HCoV-229E (including seasonality, age distribution, and coinfections with other common respiratory agents) during two consecutive calendar years and identified clinical manifestations associated with infection.

An observational, retrospective, descriptive, cross-sectional study was carried out. We analyzed nasopharyngeal aspirate (NPA) or nasopharyngeal swab (NPS) samples, obtained from patients 0 to 65 years old, hospitalized for ARI in public and private health centers in Córdoba in 2011 and 2012. The clinical specimens were handled and assayed following normal biosafety procedures and Argentina Ministry of Health recommendations implemented since the influenza A H1N1 virus pandemic in 2009. Patients were examined by a physician to identify lower respiratory infection (laryngitis, bronchiolitis, pneumonia). Patients with chronic lung disease or previous comorbidity were excluded from the study. In total, 631 patients were studied; 375 cases occurred during 2011 and 256 occurred during 2012.

Nucleic acids were extracted using a commercial kit according to the indications of the manufacturer (Axygen Scientific, Inc.). RNA extracts were used as template in a reverse transcription polymerase chain reaction (RT-PCR) assay for virus detection, using the a SuperScript III OneStep qRT-PCR System with Platinum Taq DNA Polymerase (Invitrogen), following a cycling protocol described elsewhere [26]. Specific primers targeting the $M$ protein coding region were used for HCoV-OC43 and HcoV-229E, producing amplicons of $334 \mathrm{bp}$ and $574 \mathrm{bp}$, respectively [26]. Frequency distribution was analyzed using the statistical program Infostat 2019 (https://www.infostat.com.ar/) including tests for significance of differences observed based on chi-square ( $\alpha$ : 0.05).

$\mathrm{HCoV}$ was detected in 19 out of 631 patients, indicating a prevalence of $3.0 \%$. The virus types and yearly distribution are shown in Table 1.

HCoV-229E was detected in the autumn (April and May), earlier than $\mathrm{HCoV}-\mathrm{OC} 43$, which was prevalent through the fall and winter period (March-August; Fig. 1), but there was no statistically significant difference between the frequency in 2011 and that in $2012(p=0.82)$ or between species (HCoV-OC43, $p=0.79$; HCoV-229E, $p=0.99$ ).

$\mathrm{HCoV}-\mathrm{OC} 43$ was found only in children, 13 of which were 0-5 years old and one of which was in the group of 6- to 14-year-olds, while HCoV-229E was detected at the extremes of the age range analyzed, with three patients in the 0 - to 5-year-old group and two in the oldest group (3965 years).

An analysis of co-circulation of $\mathrm{HCoV}$ with other respiratory viruses revealed evidence for both single infections and multiple infections. Co-detections occurred with RSV, HMPV, influenza A virus (Flu A) and influenza B virus (Flu B) (Table 2).

We then analyzed the association of $\mathrm{HCoV}$ infection with clinical manifestations such as recurrent obstructive bronchopathy (ROB), cyanosis, BQL, ARI, respiratory distress syndrome (RDS), community-acquired pneumonia (CAP), whooping cough or pertussis-like syndrome (PLS), pneumonia, asthma and bronchitis. No association was found when the two HCoVs were analyzed together in the year 2012 or both years combined, but HCoV-229E was significantly associated with asthma during $2011(p=0.0361)$.

This study confirms the circulation of $\mathrm{HCoV}-\mathrm{OC} 43$ and HCoV-229E in Córdoba during the years 2011-2012. The general prevalence was $3 \%$. The frequency of $\mathrm{HCoV}-\mathrm{OC} 43$ was $2.4 \%$ in 2011 and $2.0 \%$ in 2012 ; HCoV-229E was

Table 1 Frequency of HCoV-229E and HCoV-OC43 in Córdoba, Argentina, 2011-2012

\begin{tabular}{llll}
\hline Year & HCoV-229E & HCoV-OC43 & Total \\
\hline 2011 & $3 / 375(0.8 \%)$ & $9 / 375(2.4 \%)$ & $12 / 375(3.2 \%)$ \\
2012 & $2 / 256(0.8 \%)$ & $5 / 256(2.0 \%)$ & $7 / 256(2.7 \%)$ \\
Total & $5 / 631(0.8 \%)$ & $14 / 631(2.2 \%)$ & $19 / 631(3.0 \%)$ \\
\hline
\end{tabular}




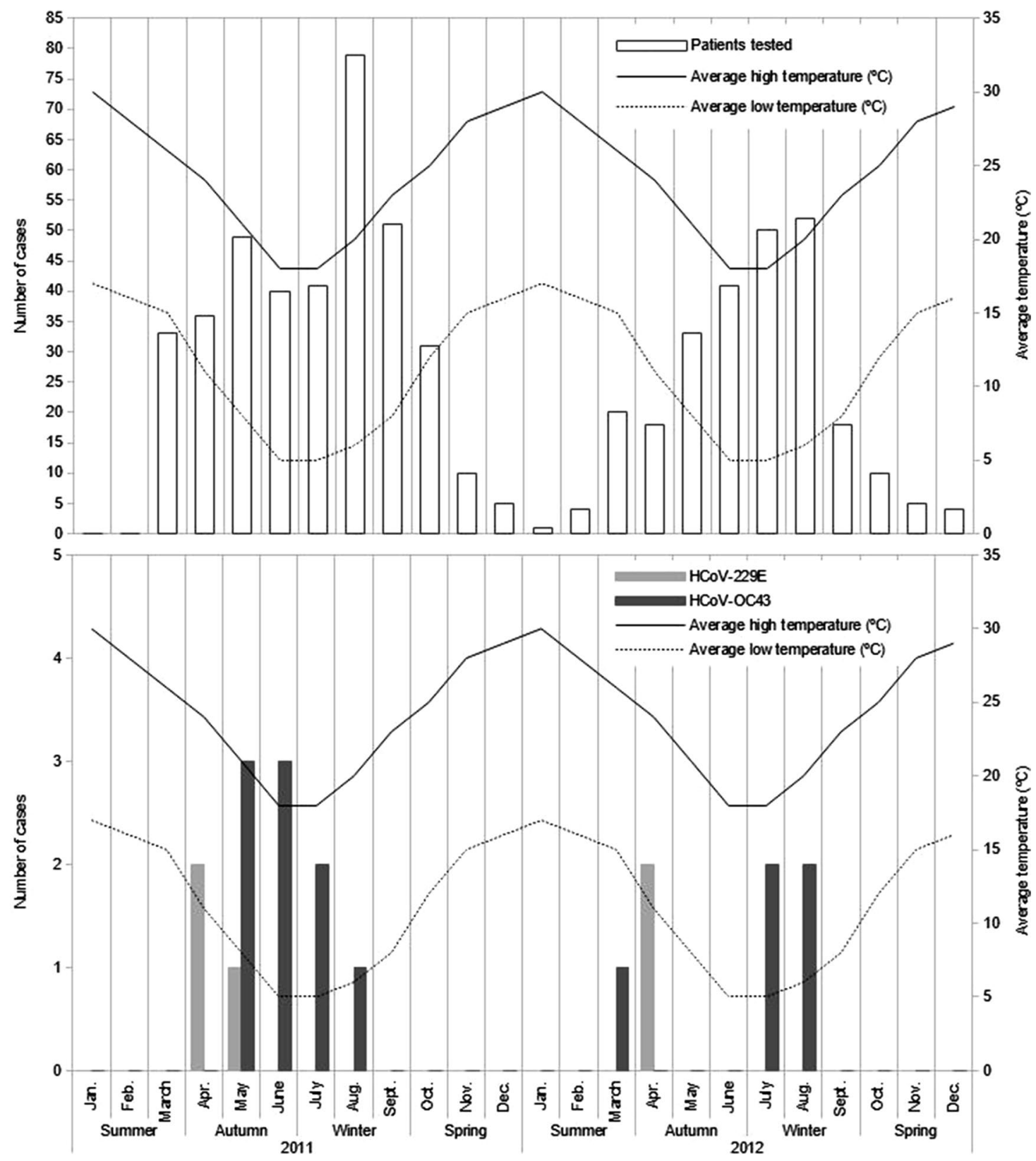

Fig. 1 Distribution of clinical specimens tested (A), cases of HCoV 229E and OC43 detected (B), and average high and low temperatures in Córdoba, Argentina, during 2011 and 2012

detected less frequently; 0.8\% in both 2011 and 2012. This detection rate in a wide-age-range group of patients including adults is similar to that reported in infants in Buenos Aires (2\%) and France (3\%) [10, 26].

The positive cases occurred during March-August, with no statistically significant difference in circulation during 2011 and 2012. However, the HCoV infection frequency can vary depending on geographical location [22]. Statistical differences were detected in $\mathrm{HCoV}-\mathrm{OC} 43$ circulation during 2009-2010 and 2011, but HCoV-229E circulation was similar when evaluated on a biennial basis [21]. Thus, in order to obtain reliable estimates to provide quality epidemiological information, it is necessary to maximize the study sample size and time period [27].

Most of the HCoV-OC43- and HCoV-229E-positive patients were children ( 0 to 14 years old), coinciding with reports showing that these viruses mainly infect children less than 5 years old [28]. However HCoV-229E was also detected in adults by us and by other authors [29]. The estimated infection rate depends on the inclusion criteria for sampling: when studies are performed with hospitalized patients only, there may be an underestimate of the 
Table 2 Infections of $\mathrm{HCoV}$ (OC43 and 229E) with other respiratory viruses in Córdoba, Argentina, during 2011-2012

\begin{tabular}{|c|c|c|c|c|}
\hline Year & Virus & $\begin{array}{l}\text { Single } \\
\text { infec- } \\
\text { tions }\end{array}$ & $\begin{array}{l}\text { Double infec- } \\
\text { tions }\end{array}$ & Triple infections \\
\hline \multirow[t]{2}{*}{2011} & $\mathrm{HCoV}-\mathrm{OC} 43$ & 3 & $\begin{array}{l}3 \text { RSV } \\
1 \text { HMPV } \\
1 \text { Flu A }\end{array}$ & $1 \mathrm{HMPV}$ and RSV \\
\hline & HCoV-229E & 3 & - & - \\
\hline \multirow[t]{2}{*}{2012} & HCoV-OC43 & 2 & $1 \mathrm{RSV}$ & $\begin{array}{l}1 \mathrm{HMPV} \text { and } \\
\text { Flu B } \\
1 \mathrm{HMPV} \text { and RSV }\end{array}$ \\
\hline & HCoV-229E & 1 & $1 \mathrm{MPVh}$ & - \\
\hline
\end{tabular}

infection rate, while the severity of disease is overestimated. The detection $\mathrm{HCoV}$ at a higher rate in young children may be related to the fact that children are taken by their parents to be examined and are admitted to the hospital even when symptoms are mild, while adults themselves consult less, and therefore epidemiological data and the clinical picture of infection are limited for adults [21, 22].

$\mathrm{HCoV}-\mathrm{OC} 43$ and $\mathrm{HCoV}-229 \mathrm{E}$ were found in single infections and coinfections, including double and triple infections. Coinfections with RSV are generally the most frequent $[19,30]$, as was seen in the present study, but importantly for the local context, about $50 \%$ of the cases were single infections.

To analyze the role of $\mathrm{HCoV}$ in respiratory pathology, we tested the statistical significance of HCoV-Oc43 and $\mathrm{HCoV}-229 \mathrm{E}$ association with respiratory diseases. We found a significant association only between $\mathrm{HCoV}-229 \mathrm{E}$ and asthma exacerbation in children, in agreement with other authors [31].

Regarding the clinical and epidemiological relevance of endemic coronaviruses, in a previously reported outbreak of human respiratory infection associated with HCoV-NL63, three out of 20 geriatric patients died [32], making epidemiological surveillance necessary in order to improve diagnosis, treatment, and prevention. The rapid and specific methods for diagnosis of ARI that are currently available have an impact on patient management and allow prevention measures to be implemented to control the spread of the agent, including intra-hospital, intrafamily and community dissemination, as well as providing information about viral strains circulating in the community [33]. This demonstrates the cost/benefit balance of performing diagnosis and incorporating these agents in the routine panel. Rapid diagnosis of respiratory viruses in hospitalized patients can result in a reduction of up to $50 \%$ in the length of the hospital stay, up to $30 \%$ in the use of ineffective, high-cost and inappropriate antibiotics, which increases bacterial resistance, and $20 \%$ in the use of other unnecessary diagnostic procedures $[34,35]$. Thus, our results can contribute to better management of ARI.

This is the first study of respiratory infections caused by $\mathrm{HCoVs}$ in Córdoba, Argentina. HCoV-OC43 and HCoV229E circulated in Córdoba during 2011-2012 and were detected in $3 \%$ of clinical cases during the cold months (March through August) as single or multiple infections. Infections occurred mainly in children less than 5 years old, but HCoV-229E was also detected in adults and was significantly associated with asthma. Therefore, further studies and surveillance are required to provide early diagnosis and better medical care of patients, as well as quality data that contribute to epidemiology modeling and prevention.

Funding This study was supported by SECyT-UNC (Grant nos. 800 dolars, 150 dolars) 2018-2021 and Fundación A. J. Roemmers (Grant nos. 500 dolars, 300 dolars) 2018-2020.

\section{Compliance with ethical standards}

Conflict of interest The authors declare that there are no competing interests.

Ethical approval This study complied with the principles outlined by the Declaration of Helsinki and was approved by an independent ethics committee (CIEIS resolution: 05/2011).

\section{References}

1. Carballal G, Videla CM, Espinosa MA et al (2001) Multicentered study of viral acute lower respiratory infections in children from four cities of Argentina, 1993-1994. J Med Virol 64:167-174

2. Santamaría C, Urueña A, Videla C et al (2008) Epidemiological study of influenza virus infections in young adult outpatients from Buenos Aires, Argentina. Influenza Other Respir Viruses 2:131-134. https://doi.org/10.1111/j.1750-2659.2008.00048.x

3. Echavarria M, Querci M, Marcone D et al (2010) Pandemic (H1N1) 2009 cases, Buenos Aires, Argentina. Emerg Infect Dis 16:311-313. https://doi.org/10.3201/eid1602.091114

4. Querci M, Stryjewski ME, Herrera F et al (2011) Healthcare personnel infected with novel influenza A H1N1 virus in university hospitals in Buenos Aires, Argentina. Scand J Infect Dis 43:7074. https://doi.org/10.3109/00365548.2010.515244

5. Marcone DN, Ricarte C, Videla C et al (2012) Rhinoviruses. Frequency in nonhospitalized children with acute respiratory infection. Medicina (B Aires) 72:28-32

6. Marcone DN, Ellis A, Videla C et al (2013) Viral etiology of acute respiratory infections in hospitalized and outpatient children in Buenos Aires Argentina. Pediatr Infect Dis J. https://doi. org/10.1097/INF.0b013e31827cd06f

7. Marcone DN, Durand LO, Azziz-Baumgartner E et al (2015) Incidence of viral respiratory infections in a prospective cohort of outpatient and hospitalized children aged $\leq 5$ years and its associated cost in Buenos Aires, Argentina. BMC Infect Dis 15:447. https:// doi.org/10.1186/s12879-015-1213-4 
8. Echavarría M, Marcone DN, Querci M et al (2018) Clinical impact of rapid molecular detection of respiratory pathogens in patients with acute respiratory infection. J Clin Virol 108:90-95. https:// doi.org/10.1016/j.jcv.2018.09.009

9. Chadha M, Hirve S, Bancej C et al (2020) Human respiratory syncytial virus and influenza seasonality patterns-early findings from the WHO global respiratory syncytial virus surveillance. Influenza Other Respir Viruses. https://doi.org/10.1111/irv.12726

10. Maffey AF, Venialgo CM, Barrero PR et al (2008) New respiratory viruses in children 2 months to 3 years old with recurrent wheeze. Arch Argent Pediatr 106:302-309. https://doi.org/10.1590/S0325 -00752008000400005

11. Lee J, Storch GA (2014) Characterization of human coronavirus OC43 and human coronavirus NL63 infections among hospitalized children $<5$ years of age. Pediatr Infect Dis J 33:814-820. https://doi.org/10.1097/INF.0000000000000292

12. Donnelly CA, Fisher MC, Fraser C et al (2004) Epidemiological and genetic analysis of severe acute respiratory syndrome. Lancet Infect Dis 4:672-683. https://doi.org/10.1016/S1473 -3099(04)01173-9

13. Hodinka RL (2016) Respiratory RNA Viruses. Microbiol Spectr. https://doi.org/10.1128/microbiolspec.dmih2-0028-2016

14. Chafekar A, Fielding BC (2018) MERS-CoV: understanding the latest human coronavirus threat. Viruses 10:93. https://doi. org/10.3390/v10020093

15. World Health Organization (2020) WHO Director-General's opening remarks at the media briefing on COVID-19-11 March 2020. WHO Dir Gen speeches 4

16. Zhou P, Lou YX, Wang XG et al (2020) A pneumonia outbreak associated with a new coronavirus of probable bat origin. Nature 579:270-273. https://doi.org/10.1038/s41586-020-2012-7

17. Tyrrell DAJ, Bynoe ML (1965) Cultivation of a novel type of common-cold virus in organ cultures. Br Med J 1:1467-1470. https://doi.org/10.1136/bmj.1.5448.1467

18. Moës E, Vijgen L, Keyaerts E et al (2005) A novel pancoronavirus RT-PCR assay: frequent detection of human coronavirus NL63 in children hospitalized with respiratory tract infections in Belgium. BMC Infect Dis 5:6. https://doi.org/10.1186/1471-2334-5-6

19. Gaunt ER, Hardie A, Claas ECJ et al (2010) Epidemiology and clinical presentations of the four human coronaviruses $229 \mathrm{E}$, HKU1, NL63, and OC43 detected over 3 years using a novel multiplex real-time PCR method. J Clin Microbiol 48:2940-2947. https://doi.org/10.1128/JCM.00636-10

20. Berry M, Gamieldien J, Fielding BC (2015) Identification of new respiratory viruses in the new millennium. Viruses 7:996-1019

21. Woo PCY, Huang Y, Lau SKP, Yuen KY (2010) Coronavirus genomics and bioinformatics analysis. Viruses 2:1805-1820

22. Lu R, Yu X, Wang W et al (2012) Characterization of human coronavirus etiology in Chinese adults with acute upper respiratory tract infection by real-time RT-PCR assays. PLoS ONE 7:e38638. https://doi.org/10.1371/journal.pone.0038638

23. Killerby ME, Biggs HM, Haynes A et al (2018) Human coronavirus circulation in the United States 2014-2017. J Clin Virol 101:52-56. https://doi.org/10.1016/j.jcv.2018.01.019
24. Su S, Wong G, Shi W et al (2016) Epidemiology, genetic recombination, and pathogenesis of coronaviruses. Trends Microbiol 24:490-502

25. Owusu M, Annan A, Corman VM et al (2014) Human coronaviruses associated with upper respiratory tract infections in three rural areas of Ghana. PLoS ONE 9:e99782. https://doi. org/10.1371/journal.pone.0099782

26. Vabret A, Mouthon F, Mourez T et al (2001) Direct diagnosis of human respiratory coronaviruses $229 \mathrm{E}$ and OC43 by the polymerase chain reaction. J Virol Methods 97:59-66. https://doi. org/10.1016/s0166-0934(01)00343-3

27. Lukšić I, Kearns PK, Scott F et al (2013) Viral etiology of hospitalized acute lower respiratory infections in children under 5 years of age - a systematic review and meta-analysis. Croat Med J 54:122-134. https://doi.org/10.3325/cmj.2013.54.122

28. Liu DX, Liang JQ, Fung TS (2020) Human Coronavirus-229E, -OC43, -NL63, and -HKU1. In: Reference Module in Life Sciences. Elsevier. https://doi.org/10.1016/B978-0-12-80963 3-8.21501-X

29. Bénézit F, Loubet P, Galtier F et al (2020) Non-influenza respiratory viruses in adult patients admitted with influenza-like illness: a 3-year prospective multicenter study. Infection. https://doi. org/10.1007/s15010-019-01388-1

30. Reina J, López-Causapé C, Rojo-Molinero E, Rubio R (2014) Clinico-epidemiological characteristics of acute respiratory infections caused by coronavirus OC43, NL63 and 229E. Rev Clin Esp 214:499-504. https://doi.org/10.1016/j.rce.2014.05.020

31. Corman VM, Muth D, Niemeyer D, Drosten C (2018) Hosts and sources of endemic human coronaviruses. In: Advances in virus research. Academic Press Inc., pp 163-188

32. Hand J, Rose EB, Salinas A et al (2018) Severe respiratory illness outbreak associated with human coronavirus NL63 in a long-term care facility. Emerg Infect Dis 24:1964-1966

33. Sui Y, Lewis GK, Wang Y et al (2019) Mucosal vaccine efficacy against intrarectal SHIV is independent of anti-Env antibody response. J Clin Investig 129:1314-1328. https://doi.org/10.1172/ JCI122110

34. Nair H, Simões EAF, Rudan I et al (2013) Global and regional burden of hospital admissions for severe acute lower respiratory infections in young children in 2010: a systematic analysis. Lancet 381:1380-1390. https://doi.org/10.1016/S0140-6736(12)61901-1

35. Shi T, McAllister DA, O'Brien KL et al (2017) Global, regional, and national disease burden estimates of acute lower respiratory infections due to respiratory syncytial virus in young children in 2015: a systematic review and modelling study. Lancet 390:946958. https://doi.org/10.1016/S0140-6736(17)30938-8

Publisher's Note Springer Nature remains neutral with regard to jurisdictional claims in published maps and institutional affiliations. 